\title{
Cryptosporidium parvum en gastrópodos silvestres como bioindicadores de contaminación fecal en ecosistemas terrestres
}

\author{
Patricia Neira O., Nelson Muñoz S., Bárbara Stanley V., Marianne Gosh C. y M. José Rosales L.
}

\section{Cryptosporidium parvum in wild gastropods as bioindicators of fecal contamination in terrestrial ecosystems}

Cryptosporidium sp oocysts were detected in snails (Helix aspersa Müller) and slug (Deroceras reticulatum Müller) from the Valparaíso Region, Chile. Snails and slug were collected from public squares and private domestic gardens. Cryptosporidium sp oocysts were recovered from faeces of both species. Ziehl Neelsen stain, nested PCR, and sequencing analysis demonstrated a profile similar to that described for genotype $\mathrm{C}$ or 2 of the parasite. These results demonstrate that snails and slug could act as a reservoir and mechanic vector of C. parvum infection for humans and animals. Moreover, gastropods could serve as bioindicators of fecal soil contamination.

Key words: Gastropods, Helix aspersa, Deroceras reticulatum, Coccidia, Cryptosporidium parvum.

Palabras clave: Gastrópodos, Helix aspersa, Deroceras reticulatum, Coccidia, Cryptosporidium parvum.

\section{Introducción}

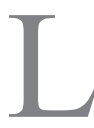

a criptosporidiosis es una infección por protozoos coccidios que afecta a los seres humanos, los animales domésticos y otros vertebrados. En los animales, especialmente en los terneros, previo a su destete, provoca una grave enteritis que ocasiona importante morbilidad, mortalidad y pérdidas económicas. En los seres humanos, surgió como una importante infección gastrointestinal en la segunda mitad de la década de los años ' 80 , junto con la aparición del SIDA. El protozoo da lugar a una infección aguda autolimitada del aparato digestivo en humanos inmunocompetentes, y una enfermedad crónica, de riesgo vital en pacientes inmunocomprometidos. En nuestra especie, varias son las vías de transmisión posibles, incluida la de persona a persona (antroponótica y la infección zoonótica), a través de la contaminación fecal del agua y los alimentos. Frecuentemente, se desconoce la fuente específica de ooquistes de Cryptosporidium implicados en la infección o en la contaminación de alimentos y agua, por carencia de investigación epidemiológica en nuestro país.

En los últimos años, el desarrollo de herramientas moleculares ha permitido detectar y diferenciar los coccidios Cryptosporidium en los niveles de especie, genotipo y subgenotipos. A la fecha, en Chile sólo se ha identificado $C$. parvum y $C$. hominis en humanos y $C$. parvum en humanos y otros vertebrados ${ }^{1}$. En personas inmunocomprometidas e inmunocompetentes de Perú,
E.U.A., Reino Unido, Portugal, Francia, Japón, Suiza, y Kenia, también se han encontrado casos humanos infectados con C. meleagridis, C. canis y C. feli ${ }^{2-9}$.

Se han observado diferencias geográficas en la prevalencia de infecciones por Cryptosporidium zoonóticos y antroponóticos ${ }^{10}$, probablemente debido a diferencias en la exposición, en la cantidad y sobrevida de los ooquistes eliminados al medio, que tiende a ser mayor para las infecciones por C. hominis que para C. parvum.

Uno de los subgenotipos de $C$. hominis se ha identificado en múltiples brotes de origen alimentario y agua en E.U.A. y el Reino Unido ${ }^{11,12}$ lo que indica que ciertos Cryptosporiodium pueden tener mayor potencial de transmisión que otros.

Cryptosporidium se encuentra en el ambiente en fase de ooquiste (ambientalmente resistente) maduro e infectante al ser excretado en las deposiciones humanas y heces de animales vertebrados infectados y es adquirido por la ingestión de agua o alimentos contaminados. En invertebrados se ha detectado en moluscos bivalvos marinos (ostras, mejillones, berberechos) $)^{13-22}$, lo que sirve como indicador de contaminación fecal de las aguas. En Chile, el estudio de 642 moluscos bivalvos (choritos, ostras, almejas, machas) y muestras de agua salada obtenidas de playas de la Región de Valparaíso, usando microscopia y pruebas moleculares no ha detectado la presencia de ooquistes de Cryptosporidium como contaminante de agua ni mariscos (Neira $\mathrm{P}$, datos no publicados). No se han realizado estudios sobre la contaminación
Universidad de Valparaíso, Chile.

Facultad de Medicina

Escuela de Medicina

Departamento de Preclínicas

Cátedra de Parasitología (PNO, NMS, BSV, MGC).

Universidad de Granada,

España.

Facultad de Ciencias

Departamento de Parasitología

Instituto de Biotecnología (MJRL).

Financiado por Dirección de Investigación de la Universidad de Valparaíso (DIPUV 01/2005)

Recibido: 16 de junio de 2009

Aceptado: 12 de mayo de 2010

Correspondencia a:

Patricia Neira Otero

patricia.neira@uv.cl 
natural con Cryptosporidium en los moluscos gastrópodos silvestres.

No existen en nuestro país normas específicas relativas a la vigilancia de la presencia de Cryptosporidium en moluscos terrestres usados para el consumo humano, debido a que la ingesta de estos gastrópodos no es una práctica culinaria habitual en el país, quedando restringida la preparación de caracoles a restaurantes y hoteles; y el helicultivo principalmente destinado a exportación.

Con el objeto de aportar antecedentes sobre la epidemiología molecular de Cryptosporidium sp en Chile, el objetivo de este trabajo fue determinar si existe infección en gastrópodos terrestres y conocer la(s) especie(s) involucrada(s) en el caracol de jardín Helix aspersa y las babosas de jardín Deroceras reticulatum, para ser usado como bioindicadores de la contaminación fecal en ecosistemas terrestres en la Región de Valparaíso, Chile $y$, eventualmente, en otros territorios.
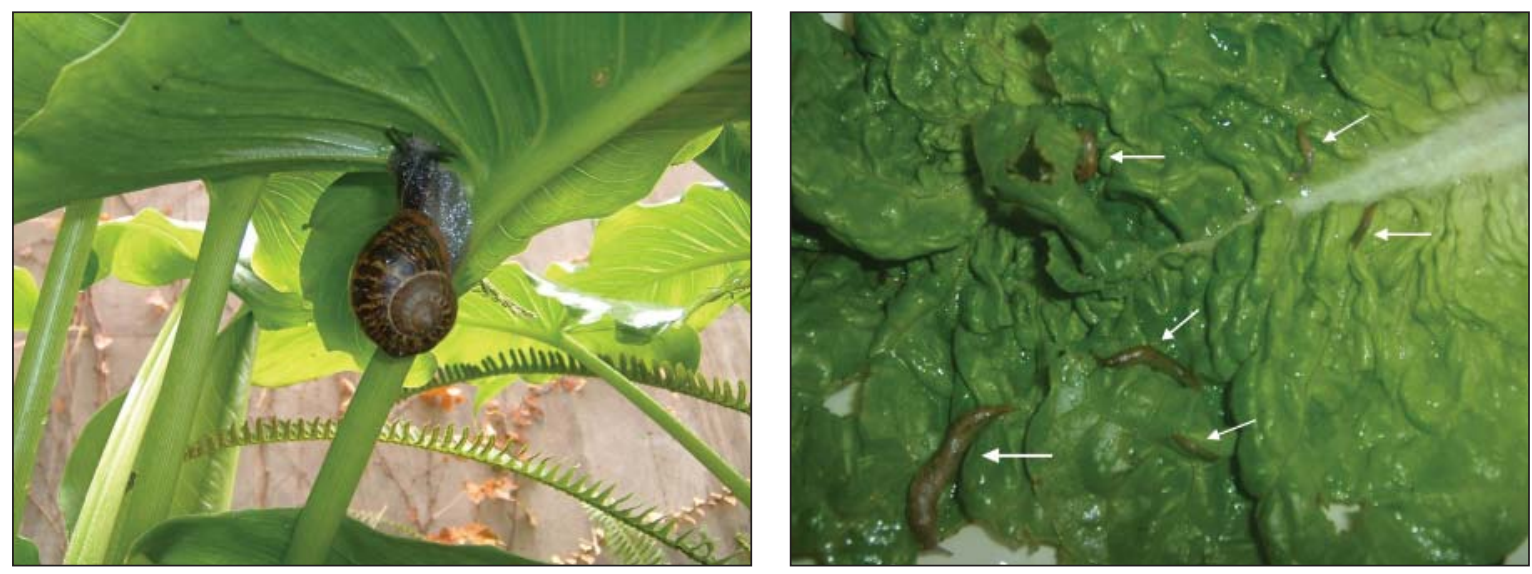

Figura 1. Caracol (Helix aspersa) en jardín (izquierda) y babosa (Deroceras reticulatum) en una hoja de lechuga (derecha).

Figura 2. Caracoles dispuestos en terrario (izquierda) y su disposición para la recolección de las fecas (derecha).

\section{Material y Métodos}

El caracol de jardín H. aspersa Müller 1774 y la babosa terrestre $D$. reticulatum Müller, son moluscos de la Clase Gastropoda. Los caracoles pertenecen al Orden Pulmonata, Familia Helicidae y las babosas al Orden Stylommatophora Familia Limacidae.

Los caracoles y las babosas (Figura 1) fueron recolectados desde lugares húmedos asociados a vegetación de plazas públicas y/o jardines de casa, donde se desarrollan y crecen naturalmente. Las babosas también fueron recolectadas de hortalizas, principalmente lechugas, adquiridas para consumo. Fueron transportados al laboratorio y dispuestos en un terrario con condiciones de luz, temperatura y humedad ambiental, posteriormente se situaron sobre una rejilla con el objeto de reunir sus deposiciones en una fuente (Figura 2).

Para determinar la presencia de ooquistes de Cryptos-
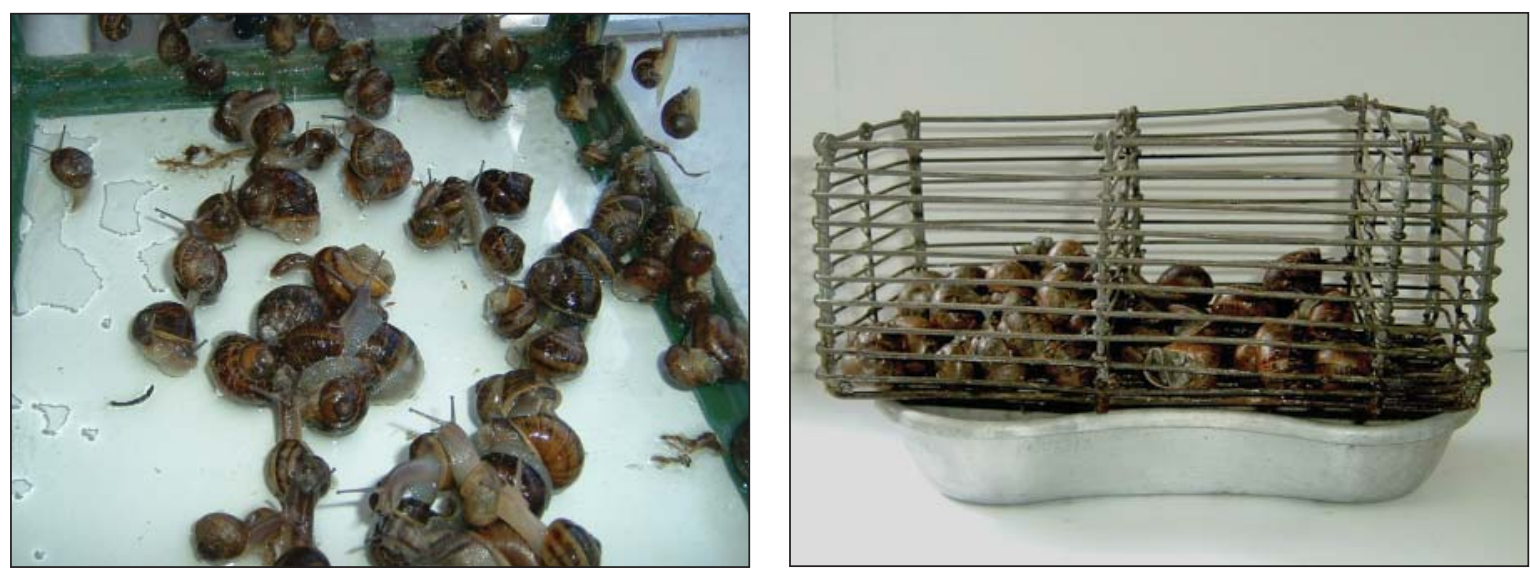
poridium se recolectó mezclas de muestras fecales por especie, las que fueron concentradas mediante centrifugación (5.000 rpm por $10 \mathrm{~min}$ ). Con el sedimento fecal se confeccionó un extendido que fue teñido con la tinción de Ziehl Neelsen modificada. Se consideró muestra positiva a aquella cuyos ooquistes de Cryptosporidium sp fueron identificados de acuerdo a sus características morfométricas.

Los ooquistes aislados de los caracoles y babosas fueron sometidos a un proceso de congelación y descongelación para su ruptura y mantenidos a $4^{\circ} \mathrm{C}$.

El ADN genómico de Cryptosporidium se extrajo de ooquistes en materia fecal mediante un kit comercial QIAamp DNA Mini Kit (QIAGEN), que usa proteinasa $\mathrm{K}$ para la digestión en tampón de lisis $\mathrm{AL}$ a $70{ }^{\circ} \mathrm{C}$ por 10 minutos, y luego una columna de intercambio iónico para su depuración y se eluye en $200 \mu 1$ de tampón AE. Se almacenó a $-20^{\circ} \mathrm{C}$ hasta su uso. La amplificación mediante RPC anidada de la subunidad $18 \mathrm{~S}$ de los genes ARNr de Cryptosporidium, se realizó de acuerdo a lo publicado por Tiangtip y cols $2002^{23}$, en $25 \mathrm{ml}$ de mezcla de reacción que contenía ADN de Cryptosporidium sin cuantificar. La primera RPC se efectuó con los partidores CR-P1: nucleótidos en las posiciones 437-456 (GenBank AF093489) y CR-P2: nucleótidos 1070-1089. El termociclado se desarrolló con una denaturación por 3 minutos a $95^{\circ} \mathrm{C}, 35$ ciclos de 94,60 y $72{ }^{\circ} \mathrm{C}$ durante 45,45 y 60 seg, respectivamente y una extensión final de 7 minutos a $72^{\circ} \mathrm{C}$. Los productos de la primera RPC fueron utilizados para una segunda RPC, usando los partidores CR-P3: nucleótidos 525-544 (GenBank AF093489) y CPBDIAGR: nucleótidos 1015-103624. Se utilizó las mismas condiciones de RPC primaria a excepción de exclusión del BSA y el termociclado se desarrollo con una denaturación por 3 minutos a $95^{\circ} \mathrm{C}, 35$ ciclos de 94,57 y $72{ }^{\circ} \mathrm{C}$ durante 30,30 y $45 \mathrm{seg}$, respectivamente y una extensión final de 7 minutos a $72{ }^{\circ} \mathrm{C}$. Los productos amplificados en la segunda RPC de la pequeña subunidad (SSU) de los genes $\mathrm{ARNr}$ de Cryptosporidium fueron visualizados mediante electroforesis en geles de agarosa al $2 \%$, teñido con bromuro de etidio bajo transiluminador UV y posteriormente fotografiados. Como control positivo, se usó ooquistes de C. parvum aislados de bovino y de pacientes VIH positivos de Chile, además se usó un control negativo ${ }^{1}$.

Las especies de Cryptosporidium fueron identificadas por secuenciación bidireccional de los productos de RPC generados por RPC anidada de la pequeña subunidad (SSU) del gen del ARNr en 4 alícuotas de ADN de cada muestra. Las secuencias fueron depositadas en GenBank.

\section{Resultados}

Se detectó ooquistes en mezclas de muestras de deposiciones de caracoles en $4 / 10$ y de babosas en $1 / 6$ sitios de recolección (Tabla 1). Ninguno de los gastrópodos de los otros sitios muestreados en la Región de Valparaíso fue positivo.

Las características de los ooquistes (tamaño, forma, superficie, y color a la tinción (Figura 3 ) fueron consistentes con las observadas en las especies de Cryptosporidium.

Los aislados de Cryptosporidium obtenidos a partir de la mezcla de muestras fecales de los caracoles y las babosas, presentaron un patrón electroforético similar al de C. parvum (Figura 4) obtenidos de bovino y pacientes con infección por VIH aislados en nuestro laboratorio para la SSU del gen del ARNr (510 pb), en concordancia con lo descrito para la especies bovina o genotipo $\mathrm{C}$.

La secuenciación y posterior comparación con lo publicado en Gen Bank mostró entre 90 y 95\% de máxima identidad. Las secuencias parciales fueron depositadas en GenBank con los No de acceso GQ355896, GQ355897 y GQ355898.

Nota: Adicionalmente se detectó en uno de los caracoles la parasitación por tres larvas de moscas de la Familia Sarcophagidae cuyo desarrollo permitió la obtención de los imagos respectivos (Figura 5).

Tabla 1. Cryptosporidium sp detectados mediante tinción de Ziehl Neelsen en mezclas fecales de gastrópodos terrestres e identificación de especie mediante RPC anidada y secuenciación

\begin{tabular}{|c|c|c|}
\hline $\begin{array}{l}\text { Helix aspersa } \\
\text { "caracol" }\end{array}$ & $\begin{array}{l}\text { n de ejemplares } \\
\text { examinados }\end{array}$ & $\begin{array}{l}\text { Presencia e identificación } \\
\text { de Cryptosporidium sp }\end{array}$ \\
\hline Jardín Valparaíso & 57 & $(-)$ \\
\hline Jardín $C^{\circ}$ Mariposas & 8 & C. parvum \\
\hline Plaza Simón Bolívar & 2 & $(-)$ \\
\hline Parque El Litre & 36 & $(-)$ \\
\hline Jardín Curauma & 67 & C. parvum \\
\hline Jardín Miraflores & 13 & C. parvum \\
\hline Jardín Quilpué & 33 & C. parvum \\
\hline Jardín Quilpué & 48 & $(-)$ \\
\hline Jardín Quilpué & 26 & $(-)$ \\
\hline Jardín V. Alemana & 51 & $(-)$ \\
\hline Total & 341 & \\
\hline $\begin{array}{l}\text { Deroceras reticulatum } \\
\text { "babosa" }\end{array}$ & $\begin{array}{c}\text { n de ejemplares } \\
\text { examinados }\end{array}$ & $\begin{array}{l}\text { Presencia e identificación } \\
\text { de Cryptosporidium sp }\end{array}$ \\
\hline Jardín Valparaíso & 4 & $(-)$ \\
\hline Plaza Simón Bolívar & 36 & $(-)$ \\
\hline Parque El Litre & 8 & $(-)$ \\
\hline Jardín Curauma & 5 & $(-)$ \\
\hline Jardín Quilpué & 3 & C. parvum $2(+)$ \\
\hline Jardín V. Alemana & 9 & $(-)$ \\
\hline Total & 65 & \\
\hline
\end{tabular}




\section{Parasitología}

Figura 3. Ooquistes de C. parvum sp obtenidos en heces de caracol Helix aspersa (izquierda) y de Deroceras reticulatum (derecha), teñidos con Ziehl Neelsen.
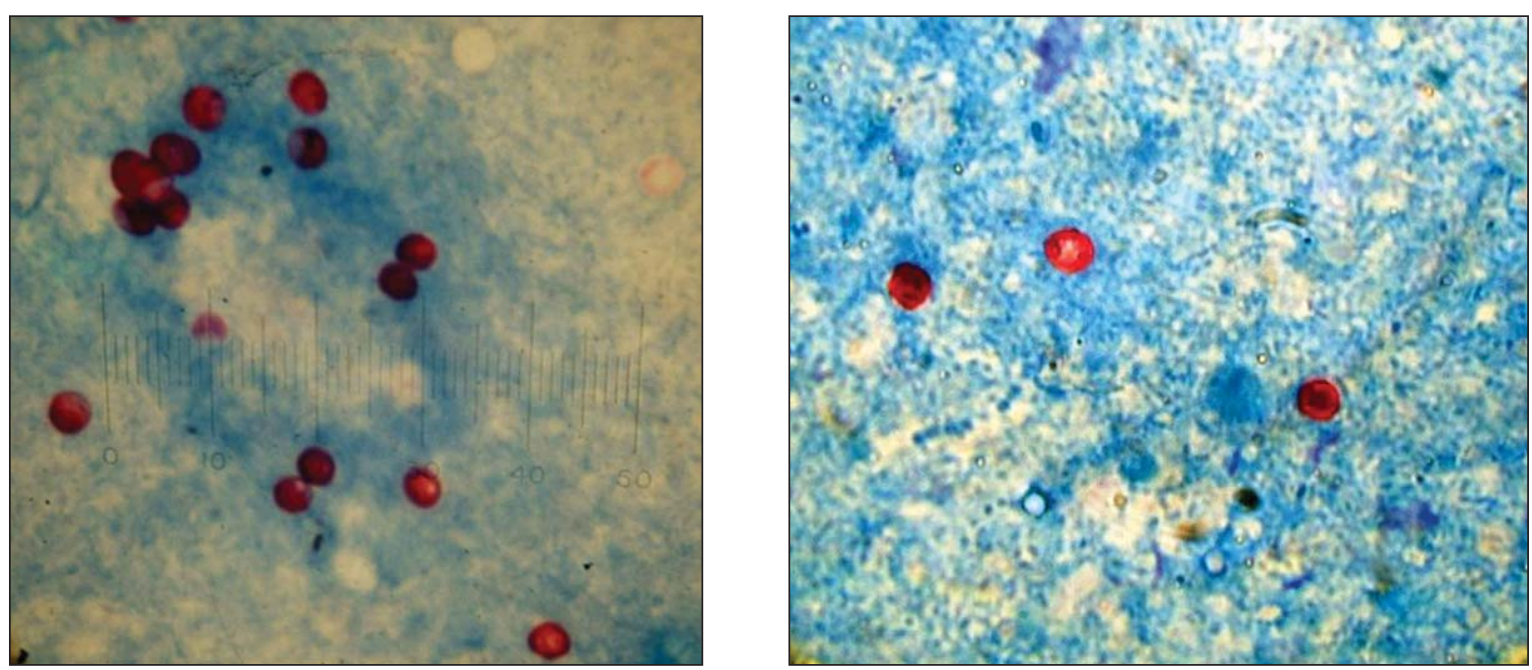

\section{Discusión}

Tanto los caracoles terrestres como las babosas, participan en el ciclo de vida de parásitos de importancia médica y veterinaria. Debido a que no existe una estricta especificidad por los hospedadores intermediarios, ambos moluscos cumplen este rol en el ciclo de nemátodos Angiostrongylus cantonensi ${ }^{25}$ y A. costarricenses que producen enfermedad en humanos. Helix aspers $a^{26}, D$. reticulatum y $D$. laeve ${ }^{27}$ se han infectado en forma natural por Angiostrongylus, cuyo primer estado larval es eliminado por las heces de roedores y los moluscos los ingieren o son infectados por penetración a través del tegumento, donde producen el tercer estado larval infectante ${ }^{28}$. En esta infección, los pacientes han manifestado el haber consumido caracoles crudos, previo a enfermar, con un período de incubación que fluctúa entre uno y 25 días $^{29}$. Otros nemátodos de importancia son las especies de los
Figura 5. Pupas e Imago de Sarcophaga sp. (Diptera: Sarcophagidae) recuperados de Helix aspersa.

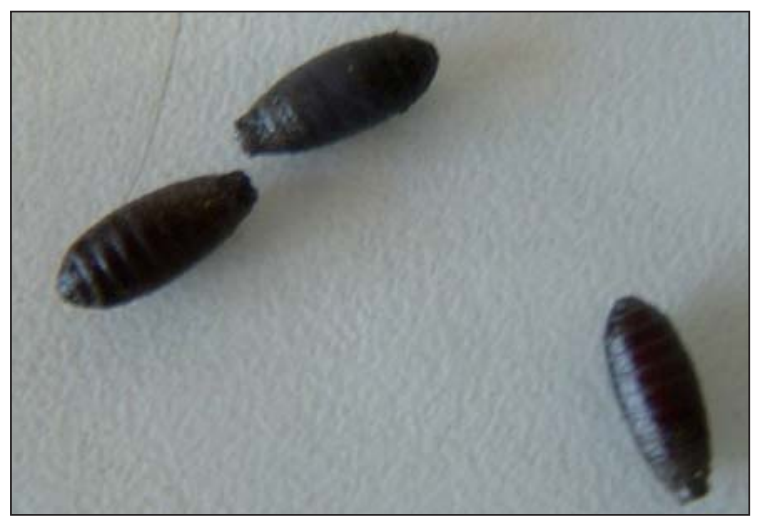

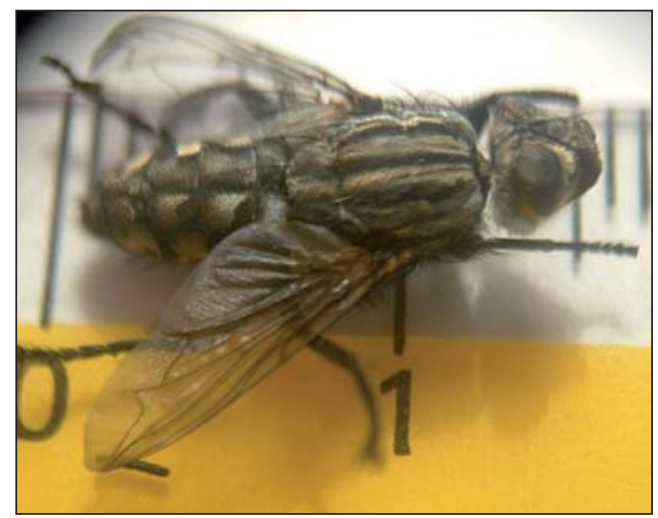

Rev Chil Infect 2010; 27 (3): 211-218 
géneros Aeleurostrongylus y Anafilaroides, parásitos pulmonares del gato doméstico; el primero de ellos presente en gatos de nuestro país ${ }^{30,31}$.

En este estudio, la presencia de ooquistes de C. parvum en caracoles y babosas silvestres se verificó mediante tinción de Ziehl Neelsen (Figura 3) e identificó mediante RPC anidada (Figura 4) y posterior secuenciación. Los ooquistes de C. parvum se detectaron por primera vez en estos moluscos gastrópodos terrestres. No existen comunicaciones previas, siendo ésta la primera.

Las características morfológicas de las posibles especies de Cryptosporidium de gastrópodos terrestres no se conocen. A la fecha, la caracterización molecular y posterior secuenciación, tal como se utiliza en este trabajo, son dos técnicas específicas para la identificación de C. parvum detectados en las muestras de agua y alimentos. El haber detectado la presencia en caracoles y babosas pone en evidencia el riesgo potencial de infección de los seres humanos y animales. Basado en fósiles, el caracol en la dieta humana se remonta al 1800 A.C. Los romanos no sólo los consumían sino que lo consideraban un remedio eficaz para enfermedades del estómago y de las vías respiratorias. Actualmente, el caracol terrestre, no así las babosas, tiene uso culinario, cosmético y terapéutico no tradicional, lo que podría ser un riesgo potencial de criptosporidiosis, si éstos estuvieran contaminados (o infectados) con Cryptosporidium sp.

Por su gran valor nutricional, los caracoles son una especie de consumo frecuente por los seres humanos en Francia y España, no así en Chile por lo que en nuestro país, desde este punto de vista parasitario, no representarían un gran riesgo para la población en sus hábitos alimenticios; sin embargo, ambas especies podrían actuar como reservorios y vectores mecánicos del coccidio Cryptosporidium para los seres humanos y los animales. $\mathrm{Si}$ bien los caracoles y sus huevos se consumen cocidos o en conserva, C. parvum corresponde a una especie que parasita a hospedadores vertebrados, lo que implica que los gastrópodos usados para el consumo humano deberían someterse a pruebas para descartar la presencia de este parásito.

En cosmética, suele usarse la baba pura o asociada con otros vehículos, sobre la piel (incluido el rostro); nuestro país la exporta principalmente a Holanda y Australia.

En países donde el consumo es habitual, la recolección silvestre o de criadero y la manipulación de caracoles, sin el adecuado manejo sanitario preventivo generaría la posibilidad de contagio con este patógeno, al ser consumidos crudos o insuficientemente cocidos en el caso de los caracoles o ingeridos accidentalmente por inadecuada manipulación de alimentos, en el caso de las babosas. El haber identificado patrones electroforéticos similares a los de C. parvum de origen bovino (Figura 4), de transmisión zoonótica, nos hace suponer que el ganado y los seres humanos, serían la principal fuente de contaminación por $C$. parvum para los gastrópodos terrestres, lo cual nos permitiría el uso de estos moluscos como biondicadores de contaminación fecal humana y/o animal en ecosistemas terrestres.

Por otra parte, los helícidos son depredados por numerosas especies de invertebrados y vertebrados domésticos como silvestres. Respecto de la salud animal, estos gastrópodos pueden constituir fuente de infección de Cryptosporidium y otros parásitos para diversas especies depredadoras de moluscos, ya que son miembros de la red trófica y fuente de alimento para vertebrados e invertebrados. Caracoles y babosas son parasitados por protozoos, helmintos y artrópodos ${ }^{32-36}$.

La alimentación de las babosas es muy variada, siendo fitófagas, también pueden consumir residuos animales. A diferencia de los caracoles, las babosas no se consumen; sin embargo, pudieran ser ingeridas inadvertidamente debido a alimentos manipulados en forma inadecuada, en especial a través de aquellos vegetales verdes que se consumen crudos y mal lavados, ya que normalmente se ubican en los pliegues de las hojas de los vegetales comestibles (Figura 1).

Las herramientas moleculares, como PCR-RFLP, indican la existencia de dos especies genéticamente distintas: C. parvum y C. hominis ${ }^{37}$, este último se encuentra exclusivamente en las infecciones humanas, es decir es una especie antroponótica, mientras que C. parvum se encuentra en los seres humanos, así como en los rumiantes domésticos, es decir, es una especie antropozoonótica.

Los marcadores moleculares utilizados en el presente estudio demostraron que los ooquistes de C. parvum aislados de caracoles y babosas en las áreas estudiadas, corresponden al genotipo $2 \mathrm{o} C$, que son los que participan en el ciclo de transmisión zoonótica de la criptosporidiosis. Posiblemente la infección de estos gastrópodos pudiera relacionarse con el uso de estiércol no descontaminado de rumiantes domésticos para la fertilización de los jardines y el contacto de los caracoles y las babosas con las heces en estos casos, podría ser permanente o casual. La inadecuada descontaminación de la tierra, una higiene inapropiada de los alimentos y la mala calidad del agua serían factores predisponentes en la presentación de esta patología enteroparasitaria.

Es difícil evaluar las implicancias de este hallazgo para la salud humana, pero podría existir riesgo de contraer criptosporidiosis por el consumo de caracoles crudos o insuficientemente cocidos y no descontaminados, especialmente en aquellos países donde la especie habitualmente tiene uso culinario. Sin embargo, la gran mayoría de los antecedentes hace recomendable su consumo cocido. Dado que en nuestro país el consumo de caracoles no es una práctica habitual, el riesgo estaría centrado en la práctica popular del uso de los caracoles depositados en 
la piel para su descamación o para que la "baba" actúe como suavizante epidérmico.

Deberían ser evaluados los vínculos epidemiológicos entre la contaminación de los moluscos silvestres terrestres con C. parvum y las enfermedades diarreicas en la población humana y animal.

La producción masiva de vegetales y animales de consumo, aunque poco contaminados o infectados, permitiría una mayor diseminación de la infección. De esta manera, los helicicultivos formados por helicolección silvestre podrían estar contaminados por protozoos parásitos y podrían infectar a los humanos que los consuman y participen en actividades propias de la producción ${ }^{38}$.

Las hortalizas y las frutas son vehículos comunes para la transmisión de enteroparásitos que utilizan el fecalismo ambiental directo como mecanismo de transmisión, como lo es Cryptosporidium. La elevada prevalencia de este coccidio en las aguas de irrigación de vegetales, sugiere fuertemente el papel de estos alimentos en la transmisión del parásito ${ }^{39}$. Se ha demostrado la presencia de ooquistes en diversos vegetales ${ }^{40}$.

Las hortalizas y frutas podrían contaminarse no sólo a través del riego con aguas servidas, sino que también a través de la presencia de heces y/o baba de caracoles y babosas contaminadas cuyas secreciones pudiesen persistir a pesar del adecuado lavado de dichas verduras.

El presente estudio es el primero en comunicar la presencia de ooquistes de $C$. parvum en gastrópodos terrestres $H$. aspersa y $D$. reticulatum en Chile (Figura 3) y la literatura científica no contiene reportes de casos de criptosporidiosis humana provocada por el consumo de estos moluscos.

A pesar de que la viabilidad de los ooquistes aislados de estos gastrópodos debe estudiarse para definir el verdadero riesgo de transmisión, este estudio puede ser de importancia para la salud pública en Chile y en los países exportadores donde son usados para su consumo, principalmente España, Francia y Portugal. Si bien en Chile no es habitual el consumo de estos gastrópodos, el uso de éstos en terapia no tradicional (basada en modas o mitos populares), podría tener implicancias para la salud. La detección de $C$. parvum en estos moluscos nos permite sugerir que podrían ser usados como bioindicadores para el monitoreo de la contaminación del medio ambiente terrestre con agentes patógenos zoonóticos o antroponóticos. Helix aspersa y D. reticulatum podrían tener un importante rol en la transmisión de C. parvum al hombre, por lo que cabría recomendar entre las medidas preventivas:

- Impedir la ingestión de caracoles o babosas crudos o insuficientemente cocidos, así como la carne cruda de otros hospederos que son depredadores de estos moluscos.

- Preconizar el lavado correcto de vegetales y frutas, el que debe incluir la eliminación de babosas y caracoles de ellas.

- No ingerir agua no potable.

- Impedir que los niños jueguen con babosas y caracoles vivos e incluso que se los lleven a la boca.

- Impedir el uso cosmético del caracol sobre la piel, especialmente del rostro.

En conclusión, hemos identificado la presencia de ADN con gran identidad a $C$. parvum genotipo zoonótico en $4 / 10$ de los grupos de caracoles y en 1/6 de los grupos de babosas (Tabla 1) estudiados en la región de Valparaíso, Chile. Este trabajo sugiere, por primera vez en Chile y el mundo que los caracoles y babosas pueden servir de reservorio o vectores mecánicos al transportar un genotipo de Cryptosporidium, que puede constituir un potencial peligro para la población. Se requiere continuar con estudios epidemiológicos que permitan entender las verdaderas consecuencias, de este hallazgo, en la salud humana y animal.

Agradecimientos: A PhD Mario Párraga, a Bióloga Sra. Victoria Devia, T.M. Sr. Ivo Carrasco por su apoyo en las técnicas moleculares y secuenciación de las mismas.

\section{Resumen}

Se detectó ooquistes de Cryptosporidium sp en caracoles (Helix aspersa Müller) y babosas (Deroceras reticulatum Müller) de la Región de Valparaíso, Chile. La recolección de caracoles y babosas se efectuó en parques públicos y jardines de diferentes hogares. Los ooquistes de Cryptosporidium sp fueron recuperados de las deposiciones de ambas especies. Después de la tinción de Ziehl Neelsen y la RPC anidada, el análisis de secuenciación demostró un patrón similar a lo descrito para el genotipo C o 2 del parásito. Estos resultados demuestran que los caracoles y babosas podrían actuar como reservorio y vectores mecánicos de la infección por Cryptosporidium. parvum para humanos y animales. Además, estos gastrópodos podrían ser usados como bio-indicadores de contaminación fecal del suelo. 


\section{Referencias}

1.- Neira-Otero P, Muñoz-Saldías N, SánchezMoreno M, Rosales-Lombardo M J. Molecular characterization of Cryptosporidium sp. and genotypes in Chile. Parasitol Res 2005; 97 : 63-7.

2.- Alves M, Matos O, Spano F, Antunes F. PCR-RFLP analysis of Cryptosporidium parvum isolates from HIV-infected patients in Lisbon, Portugal. Ann Trop Med Parasitol 2000; 94: 291-7.

3.- Morgan U, Weber R, Xiao L, Sulaiman I, Thompson R C A, Ndiritu W, et al. Molecular characterization of Cryptosporidium isolates obtained from human immunodeficiency virus-infected individuals living in Switzerland, Kenya, and the United States. J Clin Microbiol 2000; 38 (3): 1180-3.

4.- McLauchlin J, Amar C, Pedraza-Díaz S, Nichols G L. Molecular epidemiological analysis of Cryptosporidium spp. in the United Kingdom: Results of genotyping Cryptosporidium spp. in 1,705 fecal samples from humans and 105 fecal samples from livestock animals. J Clin Microbiol 2000; 38 (11): 3984-90.

5.- Xiao L, Bern C, Limor J, Sulaiman I, Roberts J, Checkley W, et al. Identification of 5 types of Cryptosporidium parasites in children in Lima, Perú. J Infect Dis 2001; 183: 492-7.

6.- Guyot K, Follet-Dumoulin A, Lelièvre E, Sarfati C, Rabodonirina M, Nevez G, et al. Molecular characterization of Cryptosporidium isolates obtained from humans in France. J Clin Microbiol 2001; 39 (10): 3472-80.

7.- Akiyoshi D, Dilo J, Pearson C, Chapman S, Tumwine J, Tzipori S. Characterization of Cryptosporidium meleagridis of human origin passaged through different host species Infect Immun 2003; 71 (4): 1828-32.

8.- Coupe S, Sarfati C, Hamane S, Derouin F. Detection of Cryptosporidium and identification to the species level by nested PCR and restriction fragment length polymorphism. J Clin Microbiol 2005; 43: 1017-23.

9.- Leoni F, Gallimore CI, Green J, McLauchlin J. Characterization of small double stranded RNA molecule in Cryptosporidium hominis, Cryptosporidium felis and Cryptosporidium meleagridis. Parasitol Int 2006; 55 (4): 299-306.

10.- Xiao L, Ryan U M. Cryptosporidiosis: an update in molecular epidemiology. Curr Opin Infect Dis 2004; 17 (5): 483-90.
11.- CDC. Surveillance for waterborne disease and outbreaks associated with recreational water United States, 2003--2004. MMWR Morb Mortal Wkly Rep 2006; 55 (No. SS-12): 1-30.

12.- Jones M, Boccia D, Kealy M, Salkin B, Ferrero A, Nichols G, et al. Cryptosporidium outbreak linked to interactive water feature, UK: Importance of guidelines. Euro Surveillance 2006, 11 (4-6): 126-8.

13.- Chalmers M, Sturdee A P, Mellors P, Nicholson V, Lawlor F, Kenny F, et al. Cryptosporidium parvum in environmental samples in the Sligo area, Republic of Ireland: a preliminary report. Letters Appl Microbiol 1997; 25 (5): 380-4.

14.- Fayer R, Lewis E J, Trout J M, Graczyk T K, Jenkins M C, Higgins J, et al. Cryptosporidium parvum in oysters from commercial harvesting sites in the Chesapeake Bay. Emerg Infect Dis 1999; 5: 706-10.

15.- Freire-Santos F, Oteiza-López A M, VergaraCastiblanco C A, Ares-Mazas E, ÁlvarezSuárez E, García-Martin O. Detection of Cryptosporidium oocysts in bivalve molluses destined for human consumption. J Parasitol 2000; 86: 853-4.

16.- Gómez-Bautista M, Ortega-Mora L M, López-Rodas V, Costas E, Tabares E. Detection of infectious Cryptosporidium parvum oocysts in mussels (Mytilus galloprovincialis) and cockles (Cerastoderma edule). Appl Environ Microbiol 2000; 66 (5): 1866-70.

17.- Lowery C J, Nugent P, Moore J E, Millar B C, Xiru X, Dooley J S. PCR-IMS detection and molecular typing of Cryptosporidium parvum recovered from a recreational river source and an associated mussel (Mytilus edulis) bed in Northern Ireland. Epidemiol Infect 2001; 127(3): 545-53.

18.- Graczyk T K, Fayer R, Lewis E J, Trout J M, Farley C A. Cryptosporidium oocysts in Bent mussels (Ischadium recurvum) in the Chesapeake Bay. Parasitol Res 1999; 85 (7): 518-21.

19.- Graczyk T K, Marcogliese D J, de Lafontaine Y, Da Silva A J, Mhangami-Ruwende B, Pieniazek, N J. Cryptosporidium parvum oocysts in zebra mussels (Dreissena polymorpha): evidence from the St Lawrence River. Parasitol Res 2001; 87 (3): 231-34.

20.- Gómez-Couso H, Freire-Santos F, MartínezUrtaza J, García Martín O, Ares-Mazás M E. Contamination of bibalve molluses by Cryptosporidium oocysts: The need for new quality control standards. Int J Food Microbiol 2003, 87: 97-105.

21.- Gómez-Couso H, Freire-Santos F, Amar C F L, Grant K A, Williamson K, Ares-Mazás M E, et al. Detection of Cryptosporidium and Giardia in molluscan shellfish by multiplexed nested-PCR. Int J Food Microbiol 2004; 91: 279-88.

22.- Gómez-Couso H, Méndez-Hermida F, Ares-Mazás E. Levels of detection of Cryptosporidium oocysts in mussels (Mytilus galloprovincialis) by IFA and PCR methods Vet Parasitol 2006; 141 (1-2): 60-5.

23.- Tiangtip R, Jongwutiwes S. Molecular analysis of Cryptosporidium species isolated from HIV-infected patients in Thailand. Trop Med Intern Health 2002; 7 (4 ): 357-64.

24.- Johnson D W, Pieniazek N J, Griffin D W, Misener L, Rose J B. Development of PCR protocol for sensitive detection of Cryptosporidium oocysts in water sample. Appl Environ Microbiol 1995; 62: 3849-55.

25.- Alicata J E. Biology and distribution of the rat lungworm, Angiostrongylus cantonensis, and its relationship to eosinophilic meningoencephalitis and other neurological disorders of man and animals. Advanc Parasit 1965; 3: 223-48.

26.- Thiengo S C, Amato S B, Aventino A, Araujo J L B. Estudo sobre os hospedeiros intermediários do Angiostrongylus costaricensis Morera and Céspedes 1971. Rev Bras Parasitol Vet 1993; 2: 64.

27.- Maurer R L, Graeff-Teixeira C, Thomé J W, Chiaradia L A, Sugaya H, Yoshimura K. Natural infection of Deroceras laeve (Mollusca: Gastropoda) with metastrongylid larvae in a transmission focus of abdominal angiostrongyliasis. Rev Inst Med Trop S Paulo 2002; 44: 53-4.

28.- Thiengo S C. Mode of infection of Sarasinula marginata (Mollusca) with larvae of Angiostrongylus costaricensis (Nematoda). Mem Inst Oswaldo Cruz 1996; 91: 277-8.

29.- Wang X, Huang H, Dong Q, Lin Y, Wang Z, Li F, et al. A clinical study of eosinophilic meningoencephalitis caused by angiostrongyliasis. Clin Med J 2002; 115 (9): 1312-15.

30.- González H, Torres P. Aelurostrongylus abstrusus en el gato doméstico. Primera comunicación en Chile. Arch Med Vet 1971; 3 : 118-24.

31.- Torres P, Hott A, Boehnwald H. Protozoos, helmintos y artrópodos en gatos de la ciudad de 
Valdivia y su importancia en el hombre. Arch Med Vet 1972; 4: 20-9.

32.- John O, Corliss J, Smith A, Foulkes J. A species of Tetrahymena from the British garden slug Milax budapestensis. Nature 1962; 196: 1008-9.

33.- Burch JB. A soil protozoan infesting land snails. Ann Rept Bull Am Malacol 1961; 27 (No paginado).

34.- Cribb T H. Introduction of a Brachylaima species (Digenea: Brachylaimidae) to Australia. Int J Parasitol 1990; 20 (6): 789-96.

35.- Conte A, Bonnet A. Sur un nématode nouveau
Angiostoma helicis n. sp. parasite de l'appareil génital d'Helix aspera (Müll). Comptes rendus des séances de la Société de biologie 1903; 55 : 198-9.

36.- Wilson M J, Glen D M, George S K. The rhabditid nematode Phasmarhabditis hermaphrodita as a potential biological control agent for slugs. Biocontrol Science and Technology 1993; 3 (4): 503- 11.

37.- Xiao L, Fayer R, Ryan U, Upton S.

Cryptosporidium Taxonomy: Recent advances and implications for public health. Clin
Microbiol Rev 2004; 17: 72-97.

38.- Fayer R. Cryptosporidium: a water-borne zoonotic parasite. Vet Parasitol 2004; 126: 37-56.

39.- Ortega Y, Roxas C, Gilman R. Isolation of Cryptosporidium parvum and Cyclospora cayetanensis from vegetables collected in markets of an endemic region in Perú. Am J Trp Med Hyg 1997; 57: 683-6.

40.- Monge R, Chinchilla M, Reyes L. Estacionalidad de parásitos y bacterias intestinales en hortalizas que se consumen crudas en Costa Rica. Biol Trop 1996; 44: 369-75. 